\title{
Some Results of the Detailed Study of the South Kuril Islands Seismicity (*)
}

\author{
S. A. Fedotov, V. N. Averuanova
}

A. M. Bagdasarova, I. P. Kusin and R. Z. Tarakanov (**)

Ricevuto il 7 dicembre 1960

In 1957-1959 the Institute of the Earth's Physics of the Academy of Sciences of the USSR carried out geophysical and geological study of the earth crust and the upper mantle and of the seismicity of the Earth in the region of Kuril Islands, Kamchatka, Okhotsk sea and the zone of the region of Kuril deep water trench (Tuskarora) in the North Pacific basin in accordance with the IGY program. The main aim was to study the transition zone from the far rast side of the Asia Continent to the Pacific Ocean $\left({ }^{1-2}\right)$. The detailed study of the seismicity itself and its connection with the deep structure in the south part of the Kuril Islands arc was one of the partial problems of the general plan.

For the purpose of earthquakes study the Institute of the Earth's Physics together with the Sakhalin Complex Research Institute of the Ac. of Sci. of the USSR two years ago organized the system of high sensitive seismic stations which continue observations in 1960 . The situation of the stations and the district of works are shown on fig. 10-11.

These stations were supplied by regional seismographs Vegik and galvanometers GB-1V $\left(M_{1}=1,0 \mathrm{~kg}, I_{1}=0,1 \mathrm{~m}, K_{1}=10^{-3} \mathrm{~kg} / \mathrm{m}^{2}\right)$. These devices are described in paper $\left({ }^{3-4}\right)$.

Registering traces of the stations have the same frequency response (fig. 1); the response is steeply cut down towards low and high frequencies which is necessary for eliminating of storm microseisms and wind noise, their level being very high on the Kuril Islands.

Each station has four registering traces. Three of them have magnification $V_{\max }=10000$. The fourth has $V_{\max }=500$. The recording

(*) Paper read at the Helsinky Assembly of the I.U.G.G. 1960. the USSR.

(**) The Institute of the Earth's Physics, Academy of Sciences of 
speed is equal to $240 \mathrm{~mm} / \mathrm{min}$. The errors in determination of absolute arrival times of seismic waves are not more than \pm 0.2 sec. which makes it possible to determine epicenters and earthquake depths more accurately. It is possible to get the information about the seismicity of studied region in short time using the described devices.

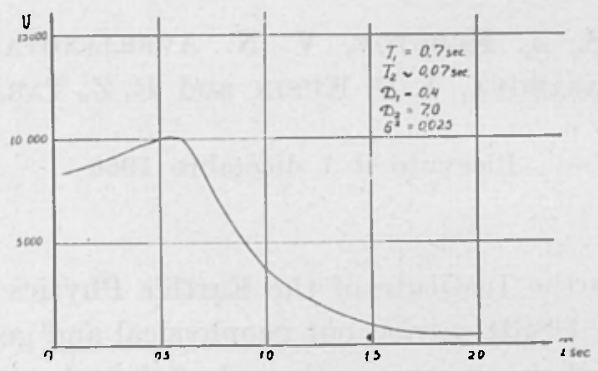

Fig. 1 - Stanclard frequency responce of a trace of a seismic Station of the South Kuril System.

At the present time the methodics to determine the source coordinates and to estimate earthquake energy in the South-Kuril zone by recordings of regional station is developed.

DETERMINATION OF RELATIONS $V=V(h), \frac{V}{V_{s}}=f(h)$ AND MASS DETERMINATION OF SOURCE COORDINATES.

In the South Kuril zone very many earthquakes happen with sources situated mainly under the Earth crust. It is necessary to allow for the refraction of seismic waves at the bottom of the crust when epicenters and source depths are being determined.

The method of "mass determination of source coordinates" suggested by U.V. Riznichenko had been chosen $\left({ }^{5}\right)$.

The method is convenient because it enables us to determine epicenters and source depths quickly and with high accuracy for any distribution of seismic wave velocities with depth. This method can be used if the law of velocity change with depth is known. That is why the study of such change preceded the mass determination of source coordinates.

The mean velocity of fictive seismic waves $V^{\prime} s-p$ in the Earth crust was determined using travel-time curves of weak earthquakes (fig. 2). It occured that in the crust of the South Kuril Islands $V^{\prime} s-p=8.4 \mathrm{~km} / \mathrm{sec}$. 
According to the preliminary data of the deep seismic sounding $\left({ }^{2}\right)$ the thickness of the Earth crust under the Kuril Islands and the adjacent shelf equal to $20-30 \mathrm{~km}$.

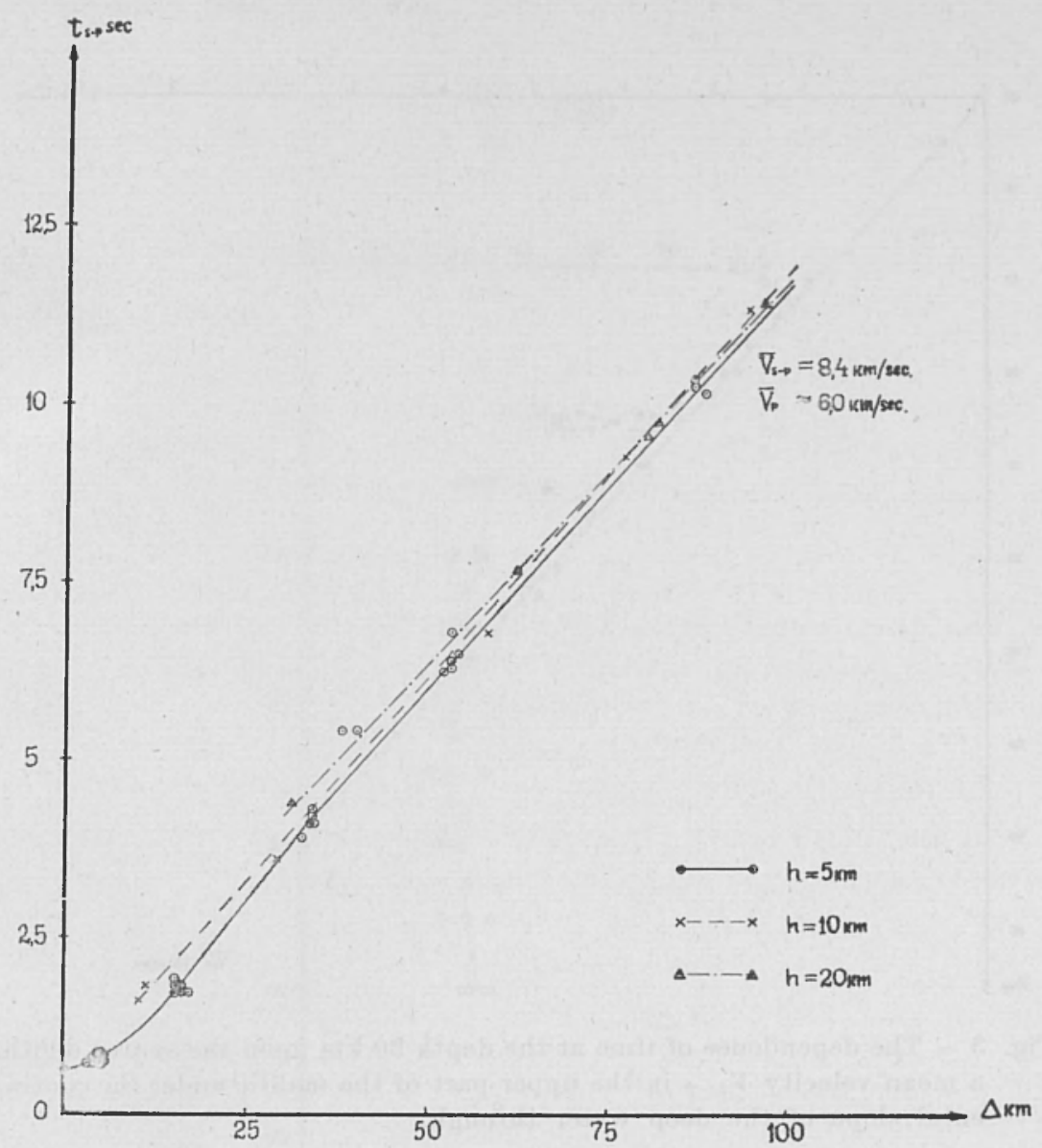

Fig. 2 - Travel time curves of earthquakes with source depths 5,10 and $20 \mathrm{~km}$. Mean velocities of seismic waves in the crust of the Iturup Island.

To determine seismic wave velocities in the upper part of the Earth mantle near earthquakes with source depth $30-120 \mathrm{~km}$ and with coordinates known with errors less than $\pm 10 \mathrm{~km}$ were used.

We did not succeed in determination seismic wave velocities in this part of the mantle by the customary method using times of seismic wave 
arrivals directly to the stations. The reason was that the velocities in the crust differed from that ones in the mantle and seismic rays refracted at the crust bottom. It is well known that velocities in the upper part of the mantle undergo a little change, (see, for example $\left(^{\circ}\right)$ ). Therefore if

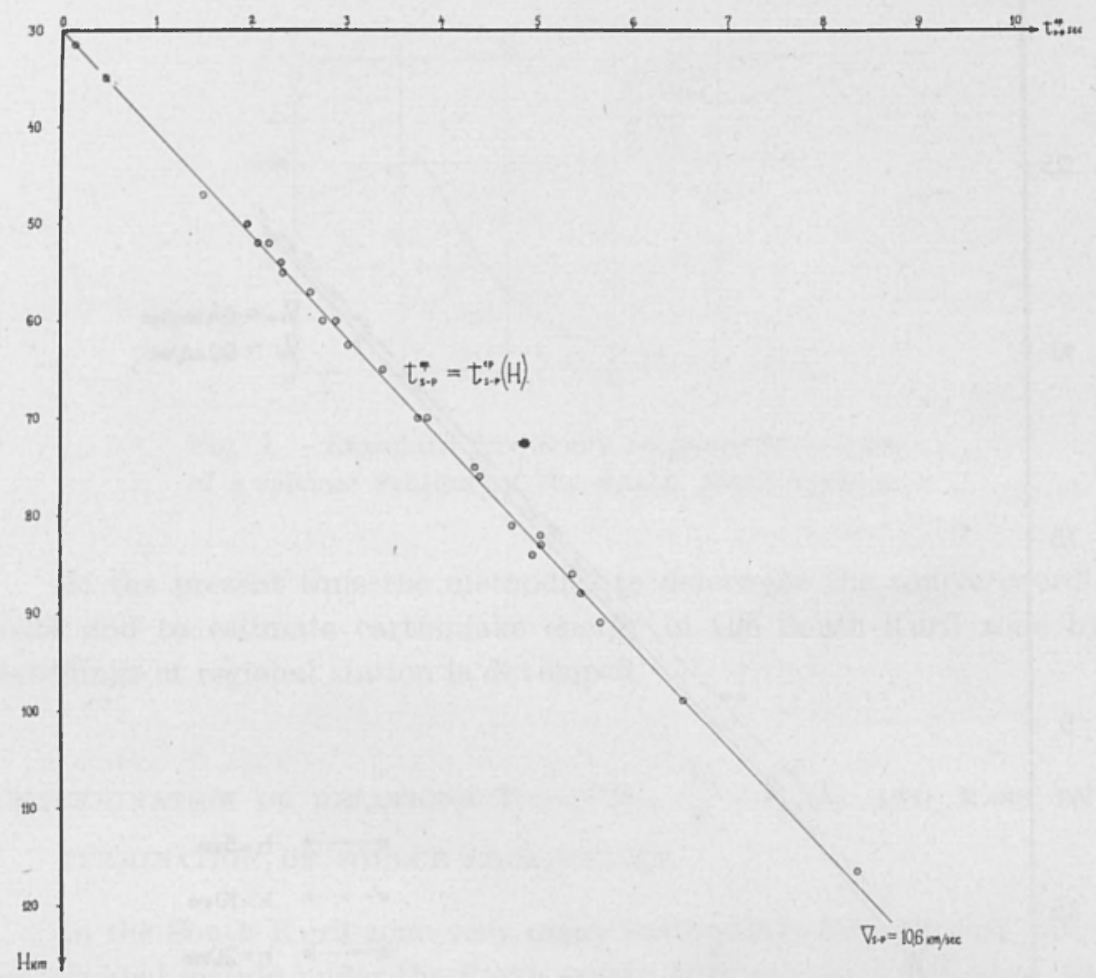

Fig. 3 - The dependence of time at the depth $30 \mathrm{~km}$ upon the source depth, a mean velocity $V_{s-p}$ in the upper part of the mantle under the continental slope of the deep water through.

the tunes of seismic waves at some depth near the crust bottom were known the problem of further determination source coordinates and velocities in the mantle would be not complicated.

In this work the times $[S-P]$ sec. recorded on the stations were recounted into the times $[S-P]^{\mathrm{H}_{1}=30}$ sec. for the depth $30 \mathrm{~km}$ under the stations using auxiliary nomograms. In this recounting the mean velocities at depths less than $30 \mathrm{~km} \nabla_{s-p}^{\prime}=8,5 \mathrm{~km} / \mathrm{sec}, V_{p}^{\prime}=6,1 \mathrm{~km} / \mathrm{sec}$. 
and at depth more than $30 \mathrm{~km} \bar{V}_{s-p}^{\prime \prime}=10,5 \mathrm{~km} / \mathrm{sec} ., \bar{V}_{p}^{\prime \prime}=7,8 \mathrm{~km} / \mathrm{sec}$. were accepted. It can be show that if:

1) the errors in a preliminary determination of source coordinate are not more than $\pm 10 \mathrm{~km}$,

$$
\frac{V_{p}}{V_{S}}=f(h)
$$

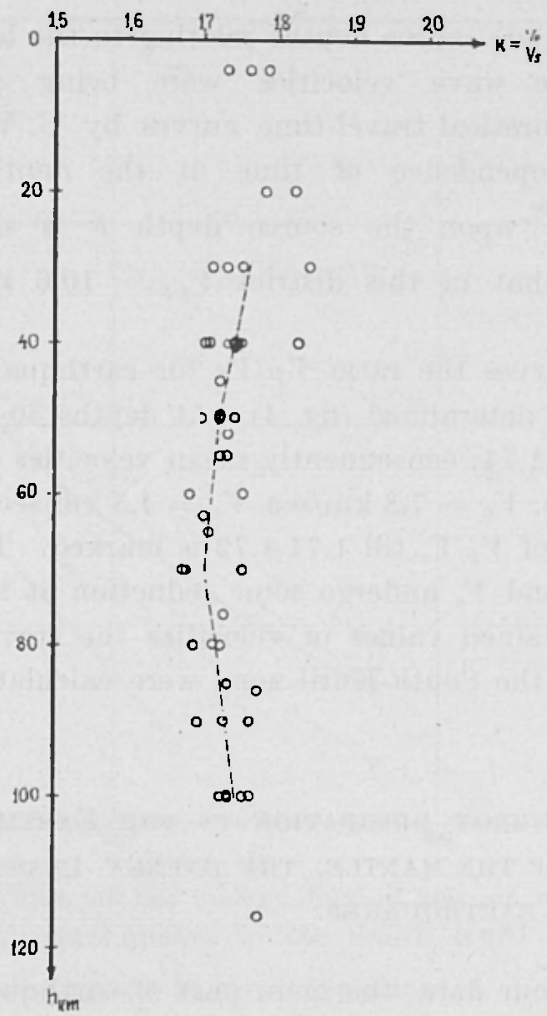

Fig. 4 - The relation $V_{p} / V_{s}=f(h)$ for South-Kuril earthquakes.

2) the mean velocity in the crust changes in the range $8.25 \mathrm{~km} / \mathrm{sec}$. $<V_{s-p}^{\prime}<8.75 \mathrm{~km} / \mathrm{sec}$,

3) the depth of the Mochorovichich boundary changes in the range $25 \mathrm{~km}<H$ Mocho $<35 \mathrm{~km}$; 
4) the mean velocity in the upper part of the mantle changes in the range $10.25 \mathrm{~km} / \mathrm{sec} .<\bar{V}_{s-p}^{\prime \prime}<10.75 \mathrm{~km} / \mathrm{sec}$.

then the errors in recounting are not more than +0.2 sec. The errors in determination of arrival times using the records of the South Kuril system are of the same order. Consequently the described recounting is admissible.

After the recounting arrival times to the depth $30 \mathrm{~km}$ the new more precise - epicenter position was determined by use of several methods.

At the same time source depths relating to the level $H_{1}=30 \mathrm{~km}$, and mean seismic wave velocities were being determined using the method of theoretical travel-time curves by U. V. Riznichenko ( ${ }^{5}$ ). On fig. 3 the dependence of time at the depth $30 \mathrm{~km}$ under the epicenter $t_{i p}^{H_{1}=30}$ upon the source depth $h$ is shown. If follows from this curve that in this district $\bar{V}_{s \cdot p}=10.6 \mathrm{~km} / \mathrm{sec}$. at depths $30-100 \mathrm{~km}$.

By Vadati curves the ratio $V p / V s$ for earthquakes with different source depths was determined (fig. 4). At depths $30-100 \mathrm{~km}$ the mean value of $V p / V s \approx 1.74$; consequently mean velocities of $P$ and $S$ waves at these depths are: $\bar{V}_{p}=7.8 \mathrm{~km} / \mathrm{sec} . \bar{V}_{s}=4.5 \mathrm{~km} / \mathrm{sec}$. At depths $50-80$ $\mathrm{km}$ the reduction of $V_{p} / V_{s}$ till 1.71-1.72 is marked. This means that if $V_{s \cdot p}=$ const $V_{p}$ and $V_{s}$ undergo some reduction at these depths.

Using the obtained values of velocities the travel time curves of seismic waves for the South-Kuril zone were calculated.

SEISMIC WAVES ENERgY DISSIPATION IN THE EARTH CRUST AND THE UPPER PART OF THE MANTLE, THE ENERGY CLASSIFICATION OF THE SOUTH KURIL EARTHQUAKES.

According to our data, the main part of earthquakes in the South Kuril Islands occur under the crust at depths 30-120 km. To all appearance the sources are situated higher as well as deeper the upper boundary of "asthenospere" where - according to Shebalin data $(7,8)$ the screening or very strong energy dissipation begins. It is well known that magnitudes $M$ of Kuril-Kamchatka earthquakes are anomally reduced when $M$ are determined by use of the Fare-Eostern stations data $\left(^{\theta}\right)$. This anomaly is caused apparently by peculiarities in the structure of the upper part of the globe in the Island arc region. 
Consequently it was impossible to use any ready scale to determine the energy of near undercrust earthquakes in this region. Evidently this classification must be carried out estimating the body waves energy.

In the best case it is possible to draw experimental curves $\varepsilon=\varepsilon(r)$ not nearer to the source than $r=h$ where $h$ is the source depth, $\varepsilon$ is the seismic waves energy flux per unit area, $r$-hypocentral distance.

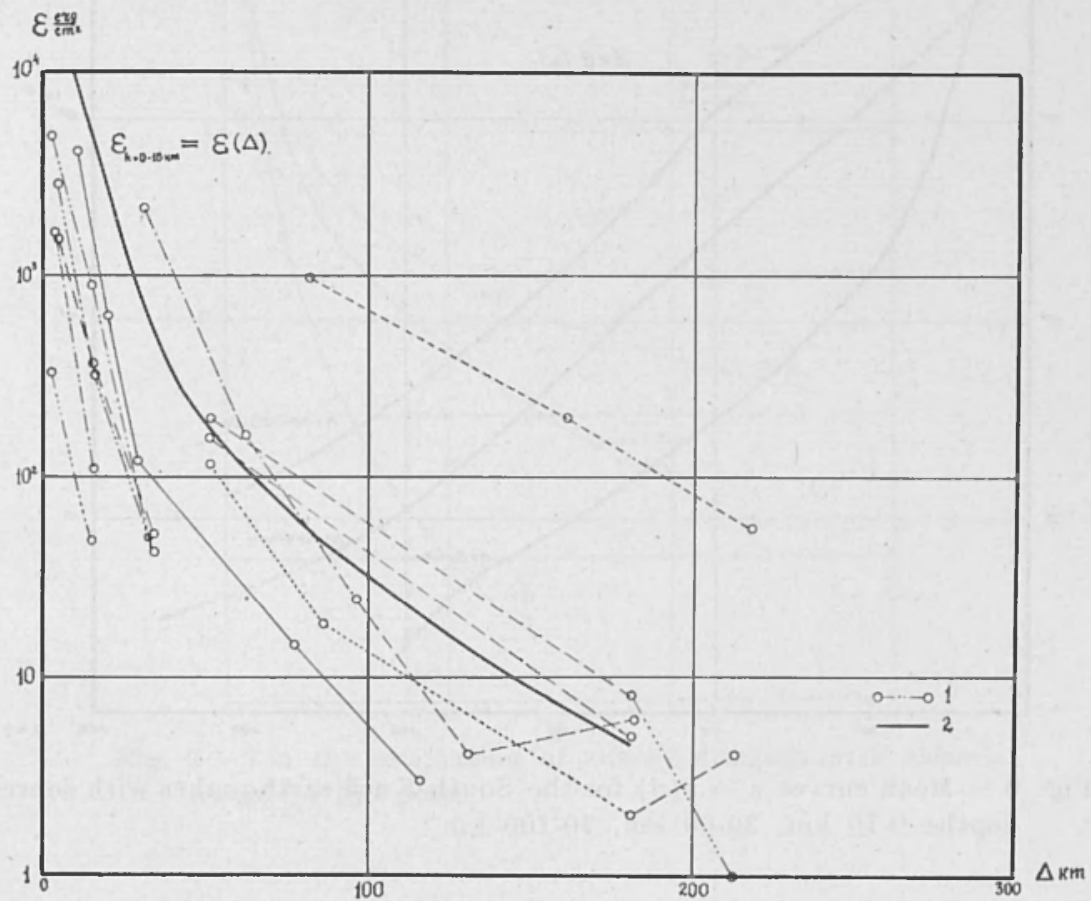

Fig. 5 - The reduction of the energy flux of seismic waves with distance $\varepsilon=\varepsilon(\Delta)$ for weak earthquakes in the South Kuril Islands crust.

1) for separate earthquakes; 2) the mean curve.

To estimate the decreasing of this flux for $r<h$ it is necessary to know the geometrical divergence and chiefly the seismic waves energy dissipation in the Earth crust and in the mantle.

The dissipation of seismic waves in the crust and in the mantle can be estimated analyzing the curves $\varepsilon=\varepsilon(\Delta)$ for earthquakes with different source depths, where $\Delta-$ is an epicentral distance. The curves $\varepsilon=\varepsilon(\Delta)$ 
for earthquakes with source depths $0-10 \mathrm{~km} 30-60 \mathrm{~km}, 70-100 \mathrm{~km}$ were drawn (fig. 5,6 ). $\varepsilon$ was determined by the formula:

$$
\varepsilon=\frac{\pi^{2}}{2} \varrho \bar{V}_{s}\left[\left(\frac{\bar{A}}{T}\right)_{p}^{2} \tau_{p}+\left(\frac{\bar{A}}{T}\right)_{s}^{2} \tau_{s}\right]
$$

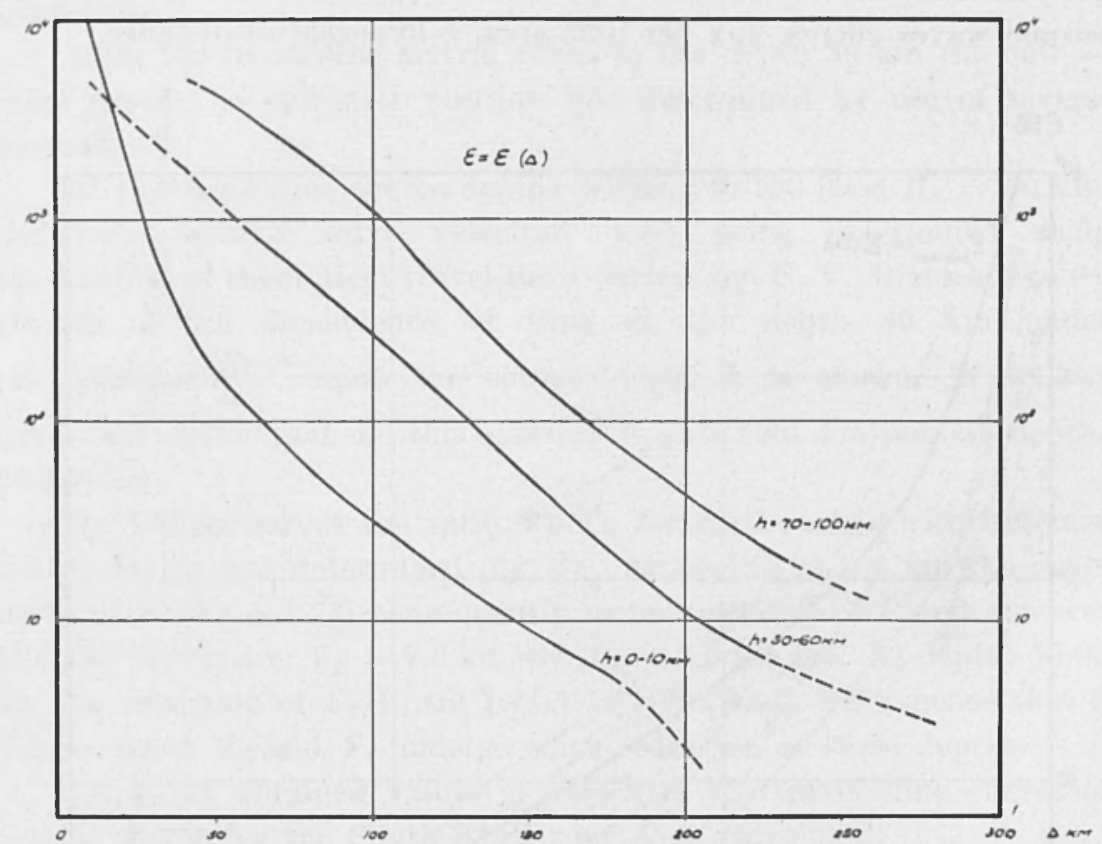

Fig. 6 - Mean curves $\varepsilon=\varepsilon(\Delta)$ for the South Kuril earthquakes with source depths $0.10 \mathrm{~km}, 30-60 \mathrm{~km}, 70-100 \mathrm{~km}$.

where $\varrho$ - the density and $V_{s}$ the mean velocity of $S$ waves at depths $0-1 \mathrm{~km}, \tau_{p, s}$ - the duration of the group of intensive vibrations in $P$ and $S$ waves, $T$ - the predominant period of waves in the group,

$$
\bar{A}=\frac{1}{n}\left\{\sum_{i=1}^{n} A_{i}^{2}\right\}^{1 / 2}
$$

where $A_{2}$ is the amplitude of a separate vibration and $n$ is the number of vibrations in the group of duration $\tau$.

The formula accounts for the doubling of amplitudes at a free boundary admitting that the main part of the energy is transported by $S H$ waves. 
The fact deserves an attention that $\varepsilon$ of undercrust earthquakes decreases with $\Delta$ as quickly as $\varepsilon$ of earthquakes in the crust (fig. 5,6 ).

Fig. 7 shows the experimental curve $\varepsilon=\varepsilon(\Delta)$ for earthquakes in the crust and theoretical curves $\varepsilon=\frac{\varepsilon_{o}}{\Delta^{2}}, \varepsilon-\frac{\varepsilon}{\Delta^{4}}$. Obviously the observed waves are not refracted waves; the energy of the last ones must

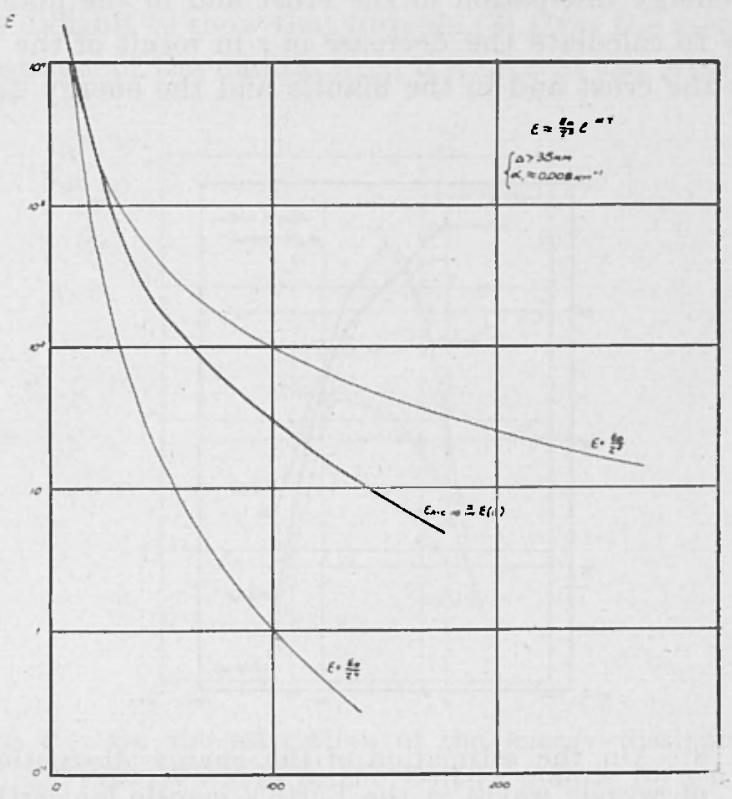

Fig. 7 - On the estimation of energy dissipation of seismic waves in the crust.

decrease quicker than $\varepsilon=\frac{\varepsilon_{o}}{\dot{\Delta}^{4}}$. The travel-time curve of these weak earthquakes (fig. 2) shows that for epicentral distances from $35 \mathrm{~km}$ till at least $100 \mathrm{~km}$ the waves may be considered as direct ones. Then we can admit that $\varepsilon(\Delta) \approx\left(\frac{\varepsilon_{o}}{\Delta^{2}}\right) e^{-a \Delta}$ for $\Delta>35 \mathrm{~km}$ and source depth $0-10 \mathrm{~km}$ where $\alpha$ is dissipation coefficient and

$$
e^{-a\left(\Delta_{2}-\Delta_{1}\right)}=\frac{\varepsilon\left(\Delta_{2}\right) \Delta_{2}^{2}}{\varepsilon\left(\Delta_{1}\right) \Delta_{1}^{2}}
$$

Using formula (2) it had been found that for $35 \mathrm{~km}<\Delta<150 \mathrm{~km}$ $\alpha_{1}=(0,009=0,001) \mathrm{km}^{-1}$. The obtained value $\alpha_{1}$ is in fact the estimation 
of energy dissipation coefficient for $S$ waves in the curst at frequencies 3-5 cps which predominated on earthquake records.

The following factors determine the value $\varepsilon(\Delta)$ for earthquake in the upper part of the mantle: a geometrical divergence of the energy from a source to an observational point, losses in result of reflection at the crust bottom, interferention at the free boundary at the point of observation, energy dissipation in the crust and in the mantle. In our case it is easy to calculate the decrease of $\varepsilon$ in result of the geometrical divergence in the crust and in the mantle and the energy dissipation in

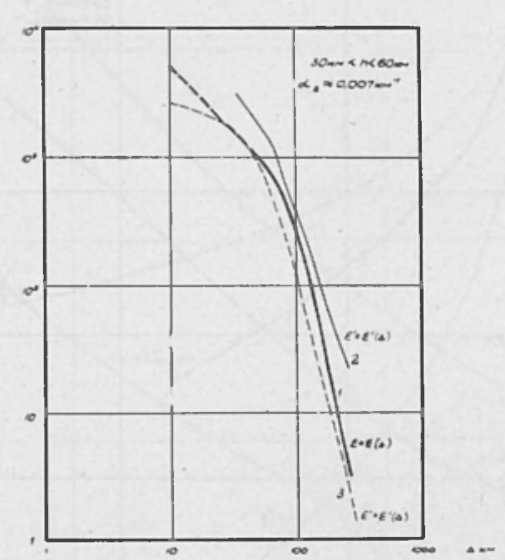

Fig. 8 - On the estimation of the energy dissipation of seismic waves in the Earth's mantle for earthquakes with source depth $30-60 \mathrm{~km}$.

1) mean experimental curve; 2) and 3) the theoretical curves drawn without allowing for the dissipation in the mantle.

the crust because the velocity distribution as a function of depth and $\alpha_{1}$, are known. The losses in energy in result of propagation through the crust bottom were accounted for by means of known coefficient $\left({ }^{10}\right)$. It had been admitted that the main part of energy is transported by $S H$ waves and consequently the change of angle of emergence does not influence much upon the form of curve $\varepsilon(\Delta)$.

Figs. 8 and 9 represent curves $\varepsilon^{\prime}=\varepsilon^{\prime}(\Delta)$ with all above mentioned factors allowed for except the dissipation in the mantle $\alpha_{2}$.

Curves N. 1 and N. 2 of figs 8 and 9 are calculated for two extreme possible variants of velocity distribution as a function of depth. $\alpha_{2}$ had 
been hound from comparing curves $\varepsilon=\varepsilon(\Lambda)$ and $\varepsilon=\varepsilon^{\prime}(\Lambda)$ by the formula:

$$
\epsilon^{\left(v_{2} r_{2}-v_{1} r_{1}\right)}=\frac{\varepsilon^{\prime}\left(\Delta_{1}\right) \varepsilon\left(\Delta_{2}\right)}{\varepsilon^{\prime}\left(\Delta_{2}\right) \varepsilon\left(\Delta_{1}\right)}
$$

where $r_{1}$ and $r_{2}$ - the lengths of path in the mantle for rays correspondingly to $\Delta_{1}$ or $\Delta_{2}$.

It is not difficult to show that formula (3) gives the mean dissipation $\bar{\alpha}_{o}$ in the thickness of the mantle from a source to the crust. It occured

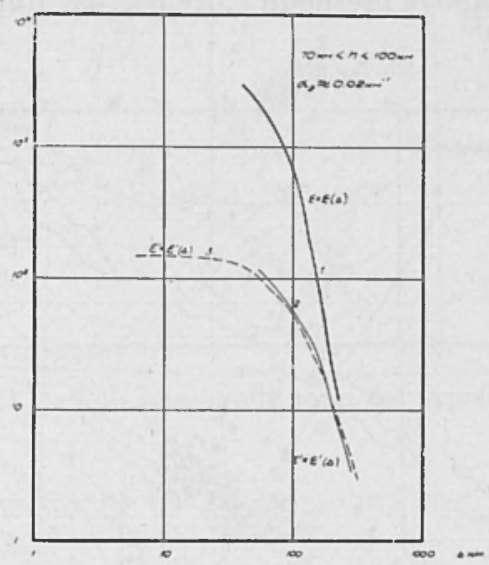

Fig. 9 - On the estimation of the energy dissipation of seismic waves in the Earth's mantle for earthquakes with source depths $70-100 \mathrm{~km}$.

1) the mean experimental curve; 2) and 3) the theoretical curves drawn without allowing for the dissipation in the mantle.

that at the depth approximately from 50 to $30 \mathrm{~km} \quad \bar{a}_{2} \approx 0.007 \mathrm{~km}^{-1}$ at a frequency near $3 \mathrm{cps}$ and at the depth from $90-80 \mathrm{~km}$ to $30 \mathrm{~km}$ $\bar{\alpha}_{2} \approx 0.020 \mathrm{~km}^{-1}$ at the same frequency. These figures indicate upon the strict increasing of energy dissipation of seismic waves deeper than approximately $50 \mathrm{~km}$.

Basing on data about the geometrical divergence, $\alpha$ and $\alpha_{2}$ the coefficiens of reflection from the crust bottom and the experimental curves $\varepsilon=\varepsilon(\Delta)$ the nomograms to classify near undercrust earthquakes of the South-Kuril zone according to body waves energy had been drawn. The curves of the nomograms are the experimental curves $\varepsilon=\varepsilon(\Delta)$ or $\varepsilon=\varepsilon(S-P)$ for earthquakes of somo given range of depths. Levels of 
curves corresponding to different energies in earthquake sources had been determined by calculating the decrease of energy flux per unit area from a source till some point at the surface of observation.

The seismicity of the South Kuril zone. The Earthquake 22 $6 . X I .1958$.

Coordinates of sources and earthquake energies are determined by use of the described above methodics. As a great number of weak earth-

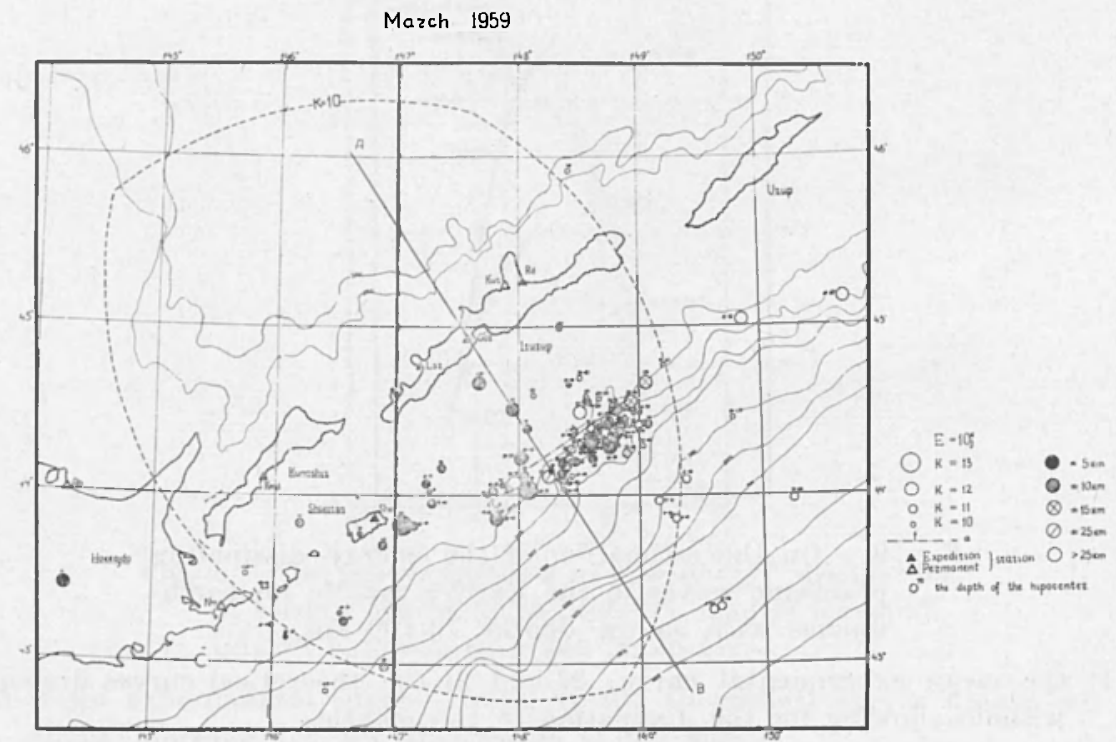

Fig. 10 - The map of epicentres of the South-Kuril zone for March 1959. Inside the dotted line all earthquakes with the energy $E \geqslant 10^{10}$ joule are plotted; " $a$ " the fault plane strike for the catastrophic earthquake of $6 . \mathrm{XI} .1958$.

quakes is registered so epicenters for separate months are mapped. Figs. 10 and 11 show two such maps. The dotted line denotes boundary of the region inside of which all earthquakes with depths $0-150 \mathrm{~km}$ and energy $E=10^{10}$ joule are clearly recorded by all regional stations and plotted on maps.

Thus maps on fig. 10-11 adequately represent the seismicity in the considered region. Fig. 12 gives the vertival cross-section of the Iturup 
Island and deep-water trench. All the earthquakes with depths determined with errors not more than $\pm 15 \mathrm{~km}$ are ploted there. Fig. 12 shows

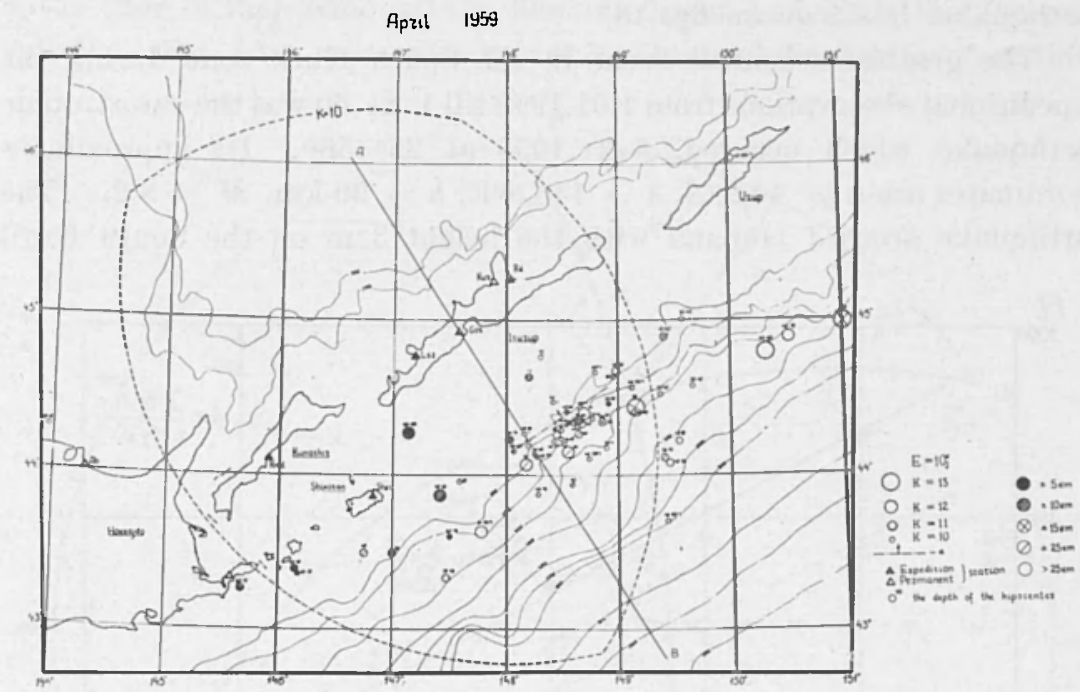

Fig. 11 - The analogous map for April 1959.

VERTICAL CROSS-sECTION OF THE EPICENTRAL ZONE FLONG THE LINE AB

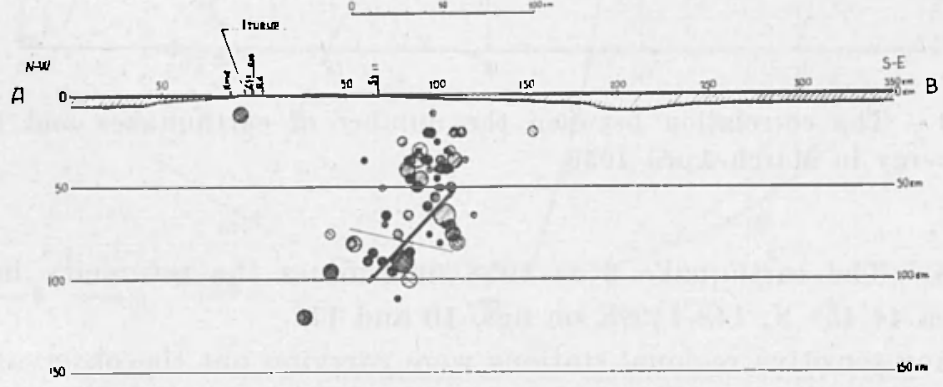

Fig. 12 - The vertical cross-section across the epicentral zone, line AB. Notations for sources are the same as on figr. 10-11.

1) direction of the fault; 2) direction of compression forces in the source of the earthquake 6.xI.1958. The true position of the source can differ from indicated on this figure because its coordinates cannot be determined accurately.

that the crust and the upper part of the mantle in the Sea of Okhotsk and under the South Kuril Islands have little seismicity in spite of an active volcanism on the islands in recent time. The epicenters are situat- 
ed mainly on the shelf side on the continental slope of the deep water trough. The dependance between the number and energy for these earthquakes is shown on fig. 13.

The greatest seismical event in the South Kuril zone during the expeditional observations from 1.01.1958 till 1 .XI .60 was the catastrophic earthquake which occured. $6 . X I .1958$ at $22^{\mathrm{h}} 58^{\mathrm{m}}$. Its approximate coordinates are $\varphi=44,2^{\circ} \mathrm{N}, \lambda=148,5^{\circ} \mathrm{E}, h=90 \mathrm{~km}, M=8.2$. The earthquake aroused tsunami with the height $3 \mathrm{~m}$ on the South Kuril

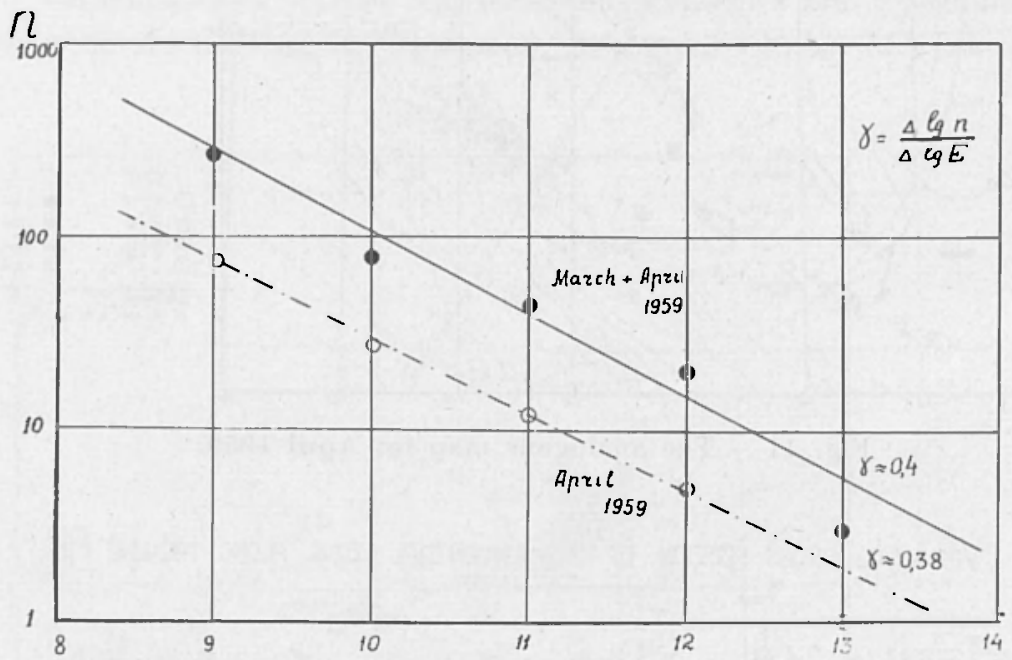

Fig. 13 - The correlation between the number of earthquakes and their energy in March-April 1959.

Islands. The earthquake 6.XI.1958 determines the seismicity inside the area $44-45^{\circ} \mathrm{N}, 148-149^{\circ} \mathrm{E}$ on figs. 10 and 11 .

Hing sensitive regional stations were carrying out the observatives near the epicentral zone of this catastrophic earthquake for 11 months till the earthquake and more than 1.5 years after it. Data are interpretated.

The source mechanism of the earthquake had been defined by V. N. Averjanova using the method of $\Lambda . V$. Vvedenskaja. Using signs of displacements in $P$ and $S$ waves of seismical stations around the epicenter two nodal planes for $P$ waves and four nodal planes for $S V$ and $S H$ waves had been drawn (fig. 14). To answer the question which of the nodal lines coincided with the fault plane and to estimate approximately the dimensions of the source the times of increasing till the first maximum 
on different stations had been used. The approximate linear dimension of the sources $2 \varrho$ can be found from the relation $2 \varrho=V_{p} \Delta t$ where $\Delta t$ is the time of increasing till the first maximum and $V_{p}$ is the $P$ waves velocity. Fig. 15 a represents values 20 obtained from data of stations

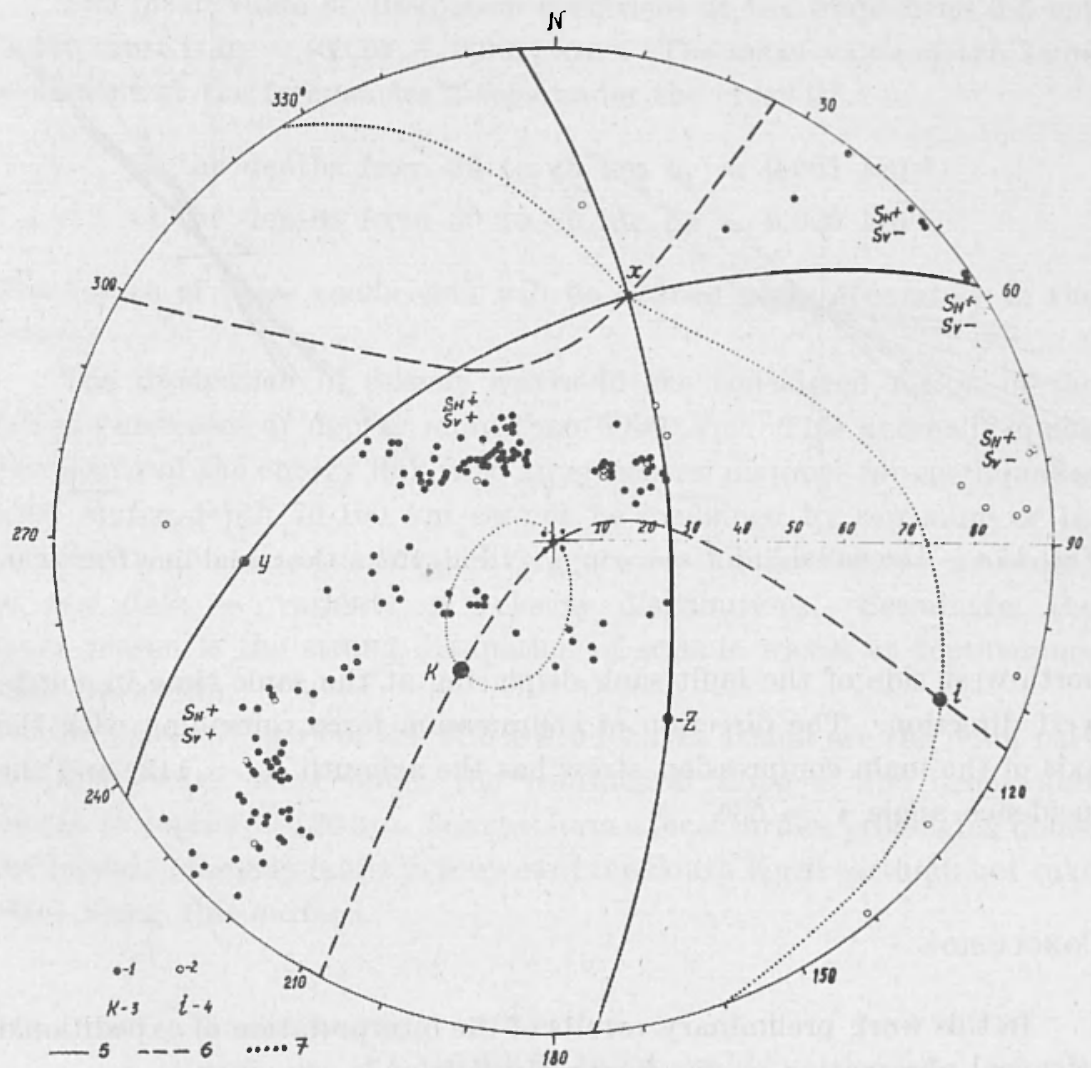

Fig. 14 - On the mecanism of the earthquake 6.XII. 1958.

1) Waves of compressions 2) waves of dilatation; 3) tension; 4) compression; 5) the nodal line $D p=0$.

for which the angle between seismic rays passing from the source and the vertical was $90^{\circ} \pm 10^{\circ}$, that is, the rays were almost in the horizontal plane. Fig. $15 \mathrm{~b}$ represents values $2 \varrho$ obtained from data of the stations with this angle being $26^{\circ}-90^{\circ}$. In the second case all the stations are situated in the sector of azimuths $296-320^{\circ}$, that is, in direction of the dip. According to figs. $15 \mathrm{a}, b$ the linear dimension of the source is $80 \mathrm{~km}$. 
The direction of fault plane strike is shown on figs. 10 and 11 , the fault plane dip is shown on fig. 12. The displacement in the sources had the character of faulting with great component along the strike. The

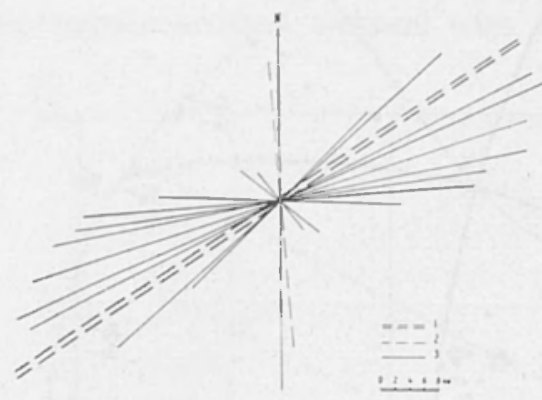

Fig. $15 a-$ the nodal line $U s h=0$.

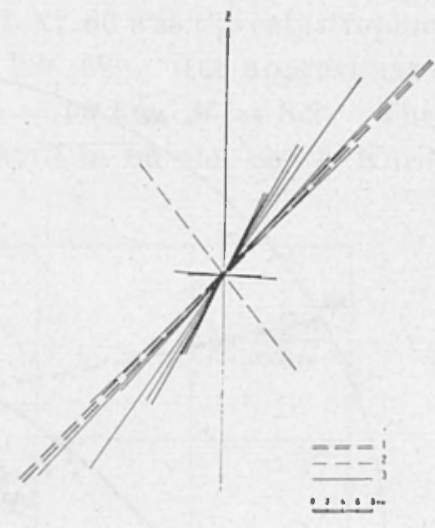

Fig. $15 b-$ the nodal line $U s v=0$.

north-west side of the fault sank displacing at the same time in southwest direction. The direction of compression force coinciding with the axis of the main compression stress has the azimuth $A_{z}=112^{\circ}$ and the incidence angle $i=53^{\circ}$.

\section{CONCLUSION}

In this work preliminary results of the interpretation of expeditional seismical observation on the South Kuril Islands are given.

Mean velocities of seismic waves in the crust are:

$$
\bar{V}_{s}=8.4 \mathrm{~km} / \mathrm{sec}, \bar{V}_{p}=6.1 \mathrm{~km} / \mathrm{sec} \text {. and } \bar{V}_{s}=3.5 \mathrm{~km} / \mathrm{sec} \text {. }
$$

Mean velocities in the upper part of the mantle under the Islands and the continental slope of the deep water trough at depths $30-100 \mathrm{~km}$. are:

$\bar{V}_{s-p}=10.6 \mathrm{~km} / \mathrm{sec}, \bar{V}_{p}=7.8 \mathrm{~km} / \mathrm{sec}, V_{s}=4.5 \mathrm{~km} / \mathrm{sec}, \bar{V}_{p} / \bar{V}_{s}=1.74$. The decreasing of $V_{p} / V_{s}$ at depths $50-80 \mathrm{~km}$ for $\bar{V}_{s-p}=$ const and predomination of velocities $V_{p}=8 \mathrm{~km} / \mathrm{sec}$. at Moho $\left({ }^{2}\right)$ withnesses for some decreasing of $V_{p}$ and $V_{s}$ with depth. 
Approximate values of dissipation coefficients of seismic waves energy are determined for the crust of the Islands and the upper part of the mantle under the Islands and the continental slope of the deep water trench.

The mean value of dissipation coefficient at the frequencies $3-5$ cps in the crust is $\alpha_{1}=(00,09 \pm 0,001) \mathrm{km}^{1}$. The mean value of the same coefficient at the frequencies $2-5 c p s$ under the crust is:

$$
\begin{aligned}
& \text { at the depths from } 30 \text { to } 45 \mathrm{~km} \alpha_{2} \approx 0,007 \mathrm{~km}^{-1} \\
& \text { at the depths from } 30 \text { to } 85 \mathrm{~km} \alpha_{2} \approx 0.020 \mathrm{~km}^{-1}
\end{aligned}
$$

The values of these coefficients will be defined more accurately in the future.

The dissipation of seismic waves in the considered region of the Islands increases at depths more than $50-60 \mathrm{~km}$. This anomally quick decreasing of the energy flux with an epicentral distance for earthquakes with source depth $70-100 \mathrm{~km}$ cannot be explained by screening or by peculiarities in a geometrical divergence for all possible - according to our data - variants of velocity distributions. Seemingly, the main reason is the strong dissipation of seismic waves at depths more than $50-60 \mathrm{~km}$.

In the south part of the Kuril-Kamchatka Island arc the main part of earthquakes occur ander the continental slope of the deep-water trough at depths $30-120 \mathrm{~km}$. Sources form a focal surface prolonging under the Islands. Largest faults in sources of the South Kuril earthquakes take place along this surface.

\section{REFERENCES}

(1) Galperin E. I., Gorjaciev A. V., Zverev S. M., Crustal Structure Research in the Transition Region from the Asiatic Continent to the Pacific. The Pacific Geologo-Geophysical Expedition USSR Academy of Sc. 1957 (XII, Seismology), 1 Moscow 1958. (in Russian).

(2) Averianov A. G., Veitsman P. S., Galperin E. T., Zaionchkovsky M. A., Zverev S. M., Koshinskaja I. P., Krakshina R. M., Mikinota G. G., Tulin A U. V., Deep Seismic Sounding carried out during the I.G.Y. in the Transition Zone from the Asiatic Continent to the Pacific. Report to the Assembly of 1960, Helsinki. (in Russian).

( ${ }^{3}$ ) Kirnos D. P., KiIARIN D. A., A Seismograph for Study of Vibrations of Constructions, Seismical Effects of Explosions and near Earthquakes. "Studia Geoph. ot Geodaet" 2 (1958). Praga (in Russian). 
(4) Medvedev S. V., An experimental Study of Vibrations of Rigid Constructions undergoing Seismical Influence. Trudy Geofiz Instituta A. N. SSSR 8 (108) (1958) (in Russian).

(5) Riznicirenko U. V., Methods of Mass Determination of Coordinates of near Earthquake Sources and Seismic Waves Velocities near Sources. "Isvetia Ac. Sc. USSR, Geoph", series, 4, (1958) (in Russian).

$\left({ }^{6}\right)$ Lehmann I., Velocities of Longitudinal Waves in the Upper Part of the Earth's Mantle. "Annales de Geophysique", 15, n. 1, (1959).

(7) Shebalin N. V., Correlation between Magnitude and Intencity of Earthquakes; Asthenosphere. Abstracts of the reports at the XI General Assambly of the International Union of Geodesy and Geophisics. Moscow 1957.

${ }^{8}{ }^{8}$ Shebalin N. V., Determination of Source Depth using Macroseismical Data allowing for Layer of reduced Velocity. Trudy of the Institute of the Earsh Physics Ac. Sc. USSR, 5, 172. (1959) (in Russian).

(') Solovjev S. L., Shein V. E., Intencity of Earthquakes according to Data of the Far East and Continental Stations of,USSR. Isvetia Ac. Sc. USSR, Geoph. ser. 9, 1959. (In Russian).

$\left({ }^{10}\right)$ Savarensky E. F. and Kirnos D. P., Elements of Seismology and Seismometry. Moscow 1955. (in Russian).

(i1) Vvedenskaia A. V., Balakina L. M. and Shirokova E. I., Report to the XII Assembly IGGY, in Helsinki. "The Study of Stresses and Faults in Earthquake Sources using Dislocation Theory" (1960) (in Russian). 